\title{
INFLUENCE OF PHOSPHORUS RUNOFF FROM AGRICULTURAL AREAS ON ENCLOSED SEA DOWNSTREAM
}

\author{
T. Yamada and T. Inoue \\ Department of Architecture and Civil Engineering, Toyohashi University of Technology, \\ 1-1 Hibarigaoka, Tempaku-cho, Toyohashi, Aichi, 441-8580, JAPAN \\ (E-mail: t-yamada@tutrp.tut.ac.jp)
}

\begin{abstract}
Agricultural area is one of the major non-point sources of phosphorus pollutants in Japan, as in many countries. In this study the runoff loading of phosphorus from agricultural lands located in the Mikawa Bay watershed in central Japan was evaluated to clarify its impact on coastal areas. Water quality and the discharge of rivers in the area were investigated in 2002. Phosphorus was mainly discharged as dissolved form in dry periods while particulate phosphorus (PP) was discharged in great quantities in storm periods in the areas. The runoff characteristics of phosphorus were the washout type, which means that the concentrations increase with the increase of discharge. There was a positive correlation between the runoff characteristics of PP and the proportion of agricultural land use. Results of experimental desorption tests with soil of the agricultural fields suggested that desorption of phosphorus from the soil can quickly occur in coastal areas, depending on the $\mathrm{pH}$ and salinity of the water body. It was estimated that about $10 \%$ of the loading of phosphorus from the areas could be quickly changed from particulate form to dissolved form in seawater.
\end{abstract}

\section{KEYWORDS}

Agricultural area; particulate; phosphorus; runoff loading

\section{INTRODUCTION}

Organic and phosphorus pollutant loadings from point sources have decreased owing to standards for emission and fundamental policy change related to the pollution load in Japan. However, phosphorus pollutant loading from non-point sources, especially agricultural areas, remain as an important problem in terms of surface water quality (Inoue et al., 1983). It has been discovered that the loading of particulate phosphorus (PP) occurs with particulate matter erosion from agricultural areas (Campbell et al., 2001); this may be the most important case in Japan because of meteorological conditions like plenty of annual rainfall and geographical conditions like steepness of river beds and the short length of rivers. The PP discharged from agricultural areas is thought to be rapidly transported to lakes or bays through the rivers. The discharged PP includes bioavailable phosphorus (Uusitalo et al., 2000), some of which dissolved by the time it reached its outlet bay or lake (Tanaka, 1994). Evaluation of the impact of agricultural activity on the water environment is essential for watershed management. But the environmental effects of the loading from agricultural areas on downstream regions are still uncertain because the characteristics and the mechanisms of runoff of phosphorus from agricultural areas to lakes or bays downstream, especially during storms, have not been sufficiently studied. Here, a survey of the water quality and discharge of rivers running through agricultural areas located in the Mikawa Bay watershed of central Japan was carried out to clarify their impacts on the downstream bodies of water. Laboratory elution experiments 
examined the soil of the area's crop fields to understand the desorption of phosphate from soil particles during storm periods.

\section{METHODS}

\section{Study site}

The studied sites were located in Toyohashi city in the central Japan on three small rivers: the Umeda river, the Hamada river, and a small channel in the watershed of the Hamada river. The rivers flow into Mikawa bay. The study area is one of the major agricultural areas in Japan. The main agricultural activities there include dry-field vegetable cultivation, especially cabbage, and livestock industries. Table 1 shows the catchment area, the usual discharge, and the land use adjacent to the rivers. There is an artificial canal named Toyogawa canal in the study area that provides water for agriculture there. The small channel area was selected as a typical agricultural area, as it is mainly used for dry-field cultivation of vegetables, flowers and ornamental plants and has no paddy fields.

\section{Field sampling and analysis}

The survey was carried out from July to October, 2002. Water samples from the three rivers were collected in polypropylene bottles about once a week. Water temperature, electric conductivity (E.C.) and water level were measured at the sites. The discharge was also measured with an electromagnetic current meter. Water sampling during a storm event was conducted at one or two-hour intervals from September 17 to 18,2002 . Water level and precipitation data were also taken during the storm event. The discharge in the storm period was calculated by the relationship of measured discharges and water levels. Analysis was made for total phosphorus (TP), dissolved total phosphorus (DP), phosphate (RP), suspended solids (SS) and principal inorganic ions (e.g., chloride ion, sulfate ion, sodium ion. The concentration of PP was calculated as the difference between TP and DP.

\section{Experiment of $P$ desorption}

The soil of the agricultural area where cabbage was mainly grown, in the watershed of the Hamada river, was collected for an experimental test on desorption of phosphorus from SS. The soil was combined with artificial seawater, which was made by adding $32 \mathrm{~g}$ of $\mathrm{NaCl}, 14 \mathrm{~g}$ of $\mathrm{MgSO}_{4} \cdot 7 \mathrm{H}_{2} \mathrm{O}$ and $0.15 \mathrm{~g} \mathrm{of} \mathrm{Na}_{2} \mathrm{CO}_{3}$ to 1 liter of filtrated river water, at a soil concentration of $2000 \mathrm{mg} / 1$. This experimental solution was mixed for 10 minutes at $200 \mathrm{rpm}$ with a labo shaker. After shaking, concentrations of TP, DP and RP were analyzed after mixing. Another test was made to clarify the effect of $\mathrm{pH}$ on desorption of phosphorus by adding $\mathrm{HCl}$ or $\mathrm{NaOH}$ to the experimental solution.

Table 1. Catchment area, usual discharge and land use.

\begin{tabular}{cccccc}
\hline \multirow{2}{*}{ River } & Catchment Area & Usual Discharge & \multicolumn{3}{c}{ Land Use } \\
& & & Agricultural & Forest & Urban, etc. \\
& $\left(\mathrm{km}^{2}\right)$ & $\left(\mathrm{m}^{3} / \mathrm{s}\right)$ & $(\%)$ & $(\%)$ & $(\%)$ \\
\hline Umeda River & 56.2 & 2.2 & 62 & 12 & 26 \\
Hamada River & 20.4 & 1.0 & 85 & 2 & 13 \\
Small Channel & 0.39 & 0.13 & 98 & 0 & 2 \\
\hline
\end{tabular}




\section{RESULTS AND DISCUSSION}

\section{Concentrations of phosphorus in the rivers}

The mean value and coefficients of variation $(\mathrm{CV})$ of the concentrations of $\mathrm{P}$ in the study period are shown in Table 2. Figure 1 shows the variations of the concentrations of TP, PP, DP and RP of the sites. The TP concentrations were about $0.6 \mathrm{mg} / \mathrm{L}$, which is more than 10 times the Japanese water quality standard for Mikawa bay $(0.05 \mathrm{mg} / \mathrm{L})$. In the Umeda river and the Hamada river, the greatest portion of TP was DP, in which RP was dominant. This may show the influence of domestic wastewater or effluent

Table 2. Mean values and coefficient of variations $(\mathrm{CV})$ of the concentrations of phosphorus $(\mathrm{mg} / \mathrm{L})$ of the rivers in the study period.

\begin{tabular}{ccccccccc}
\hline & \multicolumn{2}{c}{ Total P } & \multicolumn{2}{c}{ Dissolved P } & \multicolumn{2}{c}{ Particulate $\mathrm{P}$} & \multicolumn{2}{c}{$\mathrm{PO}_{4}{ }^{3-}-\mathrm{P}$} \\
\cline { 2 - 9 } & mean & $\mathrm{CV}$ & mean & $\mathrm{CV}$ & mean & $\mathrm{CV}$ & mean & $\mathrm{CV}$ \\
\hline Umeda River & 0.548 & 0.17 & 0.458 & 0.20 & 0.090 & 0.43 & 0.420 & 0.22 \\
Hamada River & 0.712 & 0.36 & 0.574 & 0.24 & 0.138 & 1.23 & 0.538 & 0.25 \\
Small Channel & 0.631 & 0.61 & 0.265 & 0.59 & 0.366 & 0.78 & 0.164 & 0.57 \\
\hline
\end{tabular}
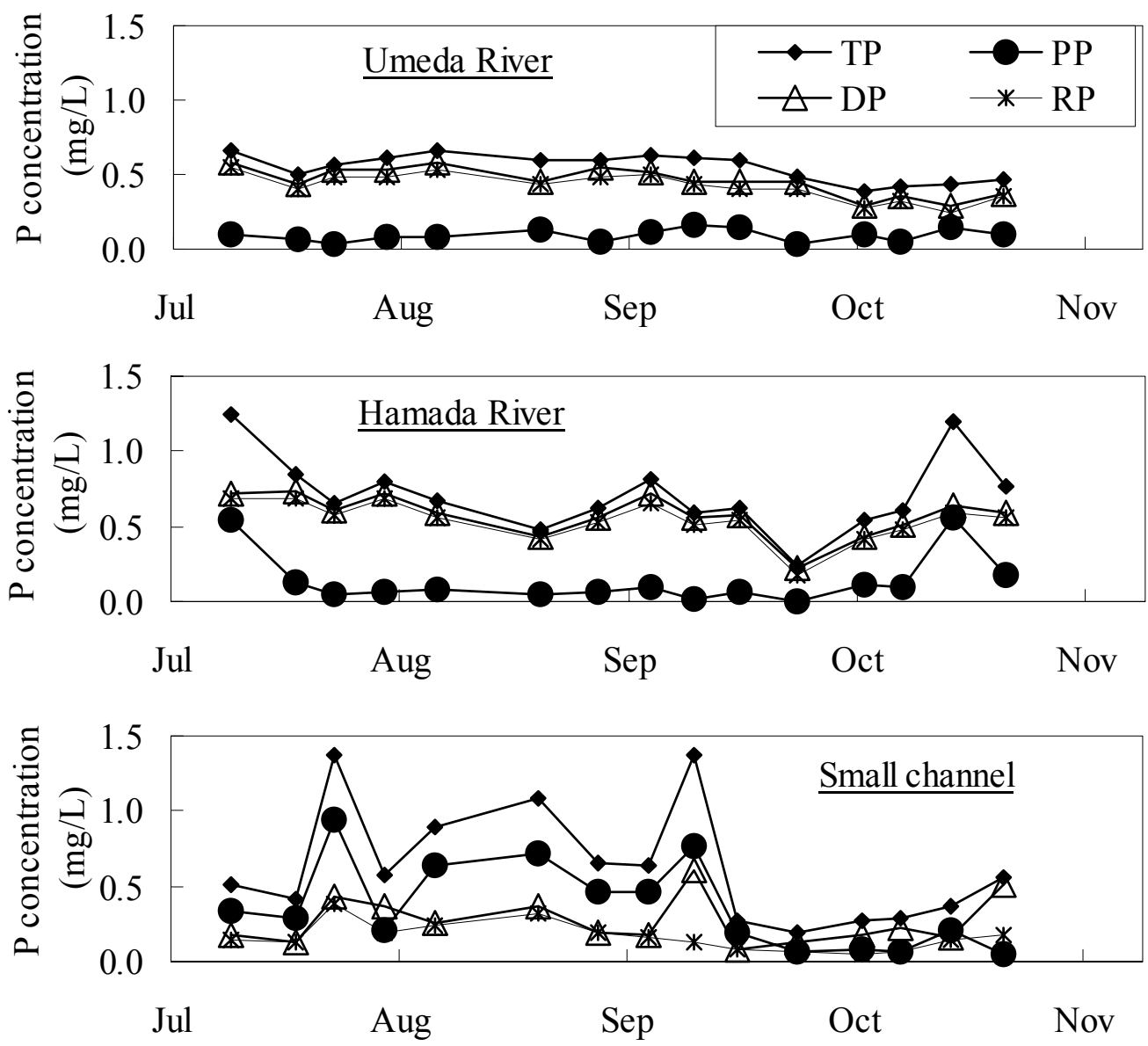

Figure 1. Variation of the concentrations of TP, PP, DP and RP of the sites. 
water from cow barns and pig houses. On the other hand, the concentrations of DP in the small channel were relatively low, and its TP concentrations varied depending on PP levels.

The variation of water quality was influenced by storm discharge. Figure 2 shows a hydrograph of the

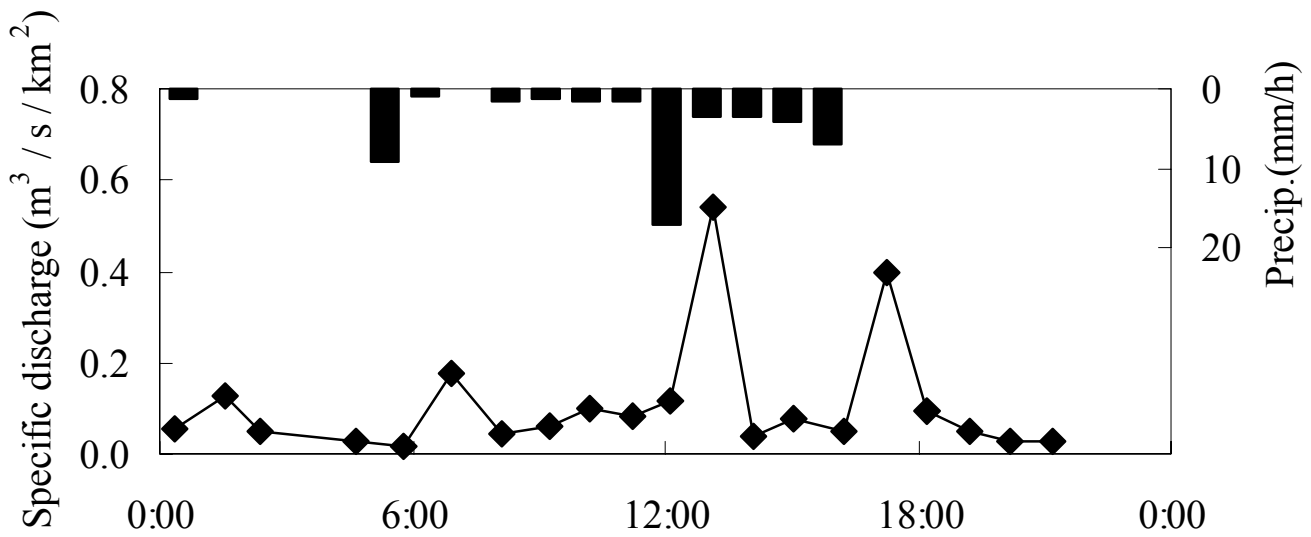

Figure. 2 Hydrograph of the small channel and hyetograph of the area during a storm event on September 17, 2002.

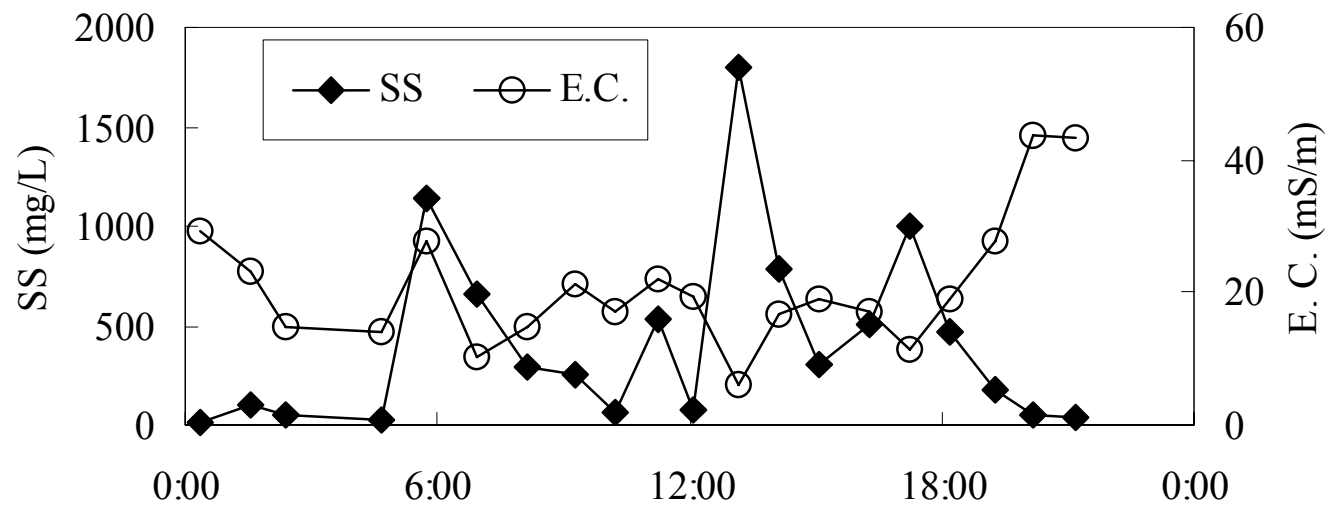

Figure. 3 Variation of concentrations of SS and E.C. in the small channel during a storm event on September 17, 2002.

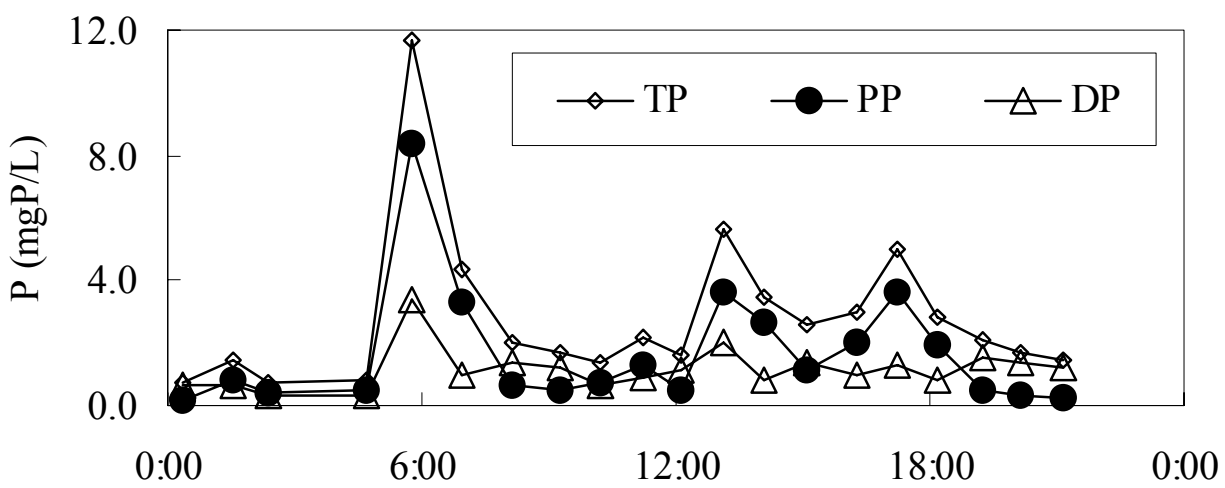

Figure. 4 Variation in the concentrations of TP, DP, and PP in the small channel during a storm event on September 17, 2002. 
small channel and a hyetograph of the area during a storm event on September 17, 2002. The total rainfall in the storm period was $52.3 \mathrm{~mm}$. The variation of discharge in the small channel corresponded with the variation of rain intensity because the watershed is small. Figure 3 shows the variation of concentrations of SS and E.C. in the channel before, during, and after the storm event. The highest concentration of SS was about $2000 \mathrm{mg} / \mathrm{L}, 100$ times more than that of the usual flow. The variation in concentrations of SS depended on the rain intensity rather than discharge of the small channel, indicating that particulates were discharged with the surface runoff of the agricultural area. On the other hand, the value of E.C. in the storm period was less than one fourth of the value in the dry period, showing that ionic components in small channel are diluted by rainwater.

Figure 4 shows the variation in the concentrations of TP, DP and PP. The concentration of TP rose to a maximum of $12 \mathrm{mg} / \mathrm{L}$ and greatly varied along with the variation of the PP in the storm period. The changes in the concentration of PP were almost the same as those of SS, which suggests that PP loading during the storm period was a result of surface soil runoff from agricultural areas. The largest portion of DP in the period was RP. The concentrations of DP weren't diluted in the period even though the concentration of DP in precipitation was as low as $0.008 \mathrm{mg} / \mathrm{L}$.

\section{Runoff loadings of phosphorus from the agricultural areas}

The relationship between the specific flow and the specific loads of components were analyzed by regression model of $L=c Q^{n}$, where $L$ is the specific load of the component (concentration multiplied by flow per catchment area, $\mathrm{g} / \mathrm{s} / \mathrm{km}^{2}$ ), $Q$ is the specific discharge (discharge per area, $\mathrm{m}^{3} / \mathrm{s} / \mathrm{km}^{2}$ ), and $c$ and $n$ are constants. Runoff types are generally classified by the constant of $n$ as washout type $(n>1$, concentration increases with increase of flow), dilution type $(n<1$, concentration decreases with increase of flow) and stable type ( $n=1$, concentration is roughly constant) (Yamada et al., 2000). Table 3 shows the constants $n$ and $c$ of the TP, PP and DP of the rivers. The $n$ values of TP were more than 1 and there were good correlations between specific loading of TP and specific discharge. The $n$ values of PP were about 2 and the runoff characteristics of PP were of the washout type. The loading of PP from agricultural

Table 3. Values of the constants $\mathrm{n}$ and $\mathrm{c}$ and the correlation coefficient(R)of the regression model of $L=c Q^{n}$, where $L$ is specific load $\left(\mathrm{g} / \mathrm{s} / \mathrm{km}^{2}\right), Q$ is specific discharge $\left(\mathrm{m}^{3} / \mathrm{s}\right)$.

\begin{tabular}{ccccc}
\hline & & $n$ & $c$ & $\mathrm{R}$ \\
\hline \multirow{3}{*}{$\mathrm{TP}$} & Umeda River & 1.51 & 2.0 & 0.93 \\
& Hamada River & 1.71 & 10.4 & 0.98 \\
& Small Channel & 1.60 & 9.7 & 0.93 \\
\hline \multirow{3}{*}{$\mathrm{DP}$} & Umeda River & 1.62 & 2.5 & 0.90 \\
& Hamada River & 1.30 & 2.1 & 0.98 \\
& Small Channel & 1.42 & 2.6 & 0.95 \\
\hline \multirow{3}{*}{$\mathrm{PP}$} & Umeda River & 1.79 & 1.2 & 0.94 \\
& Hamada River & 2.05 & 9.5 & 0.95 \\
& Small Channel & 2.15 & 14.9 & 0.92 \\
\hline \multirow{3}{*}{$\mathrm{PO}_{4}{ }^{3-}-\mathrm{P}$} & Umeda River & 1.11 & 0.6 & 0.99 \\
& Hamada River & 1.30 & 1.8 & 0.97 \\
& Small Channel & 1.09 & 1.1 & 0.97 \\
\hline
\end{tabular}




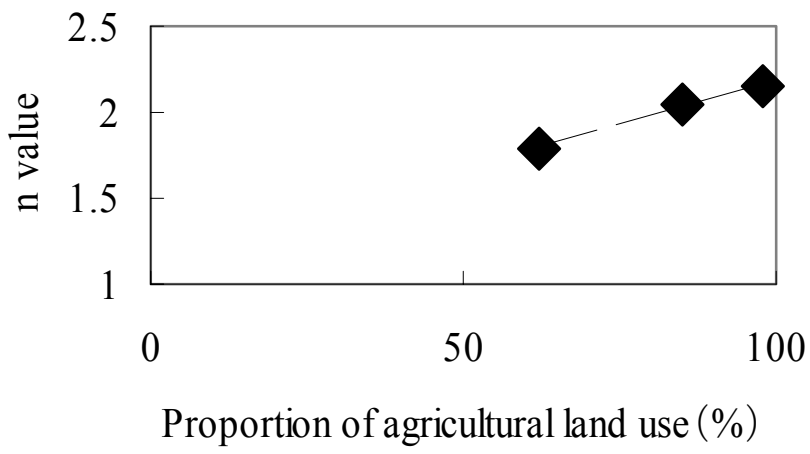

Figure 5. Relationship between the $\mathrm{n}$ value of the studied river and the proportion of agricultural land use.

areas was strongly influenced by the discharge. Figure 5 shows the relationship between the $n$ value of the studied river and the proportion of agricultural land use. There was a positive correlation between the runoff characteristics of PP and the proportion of agricultural land use, which means that agricultural areas contributed a great deal to the PP discharge.

\section{Desorption of phosphorus from particulate matters in seawater}

The TP loading from the agricultural areas was discharged largely as particulates, especially during the storm periods, and was thought to have originated from the soil in these areas. The PP discharged from the areas clearly would have run into the bay downstream during the storm period and would have had some impact on the bay. Experimental tests on the desorption of phosphorus from particulate matters were carried out in the laboratory using soil and artificial seawater. Figure 6 shows the results of a desorption test. Almost all DP was RP. About 15\% of P in the soil desorbed into the seawater while the ratio of desorption in fresh water was only about 5\%, which was caused by the occupation of sorption sites in the particulate matter by chloride ion or sulphate ion in the sea water (Liss, 1976). It was estimated that about $10 \%$ of the loading of phosphorus from the agricultural areas could be quickly

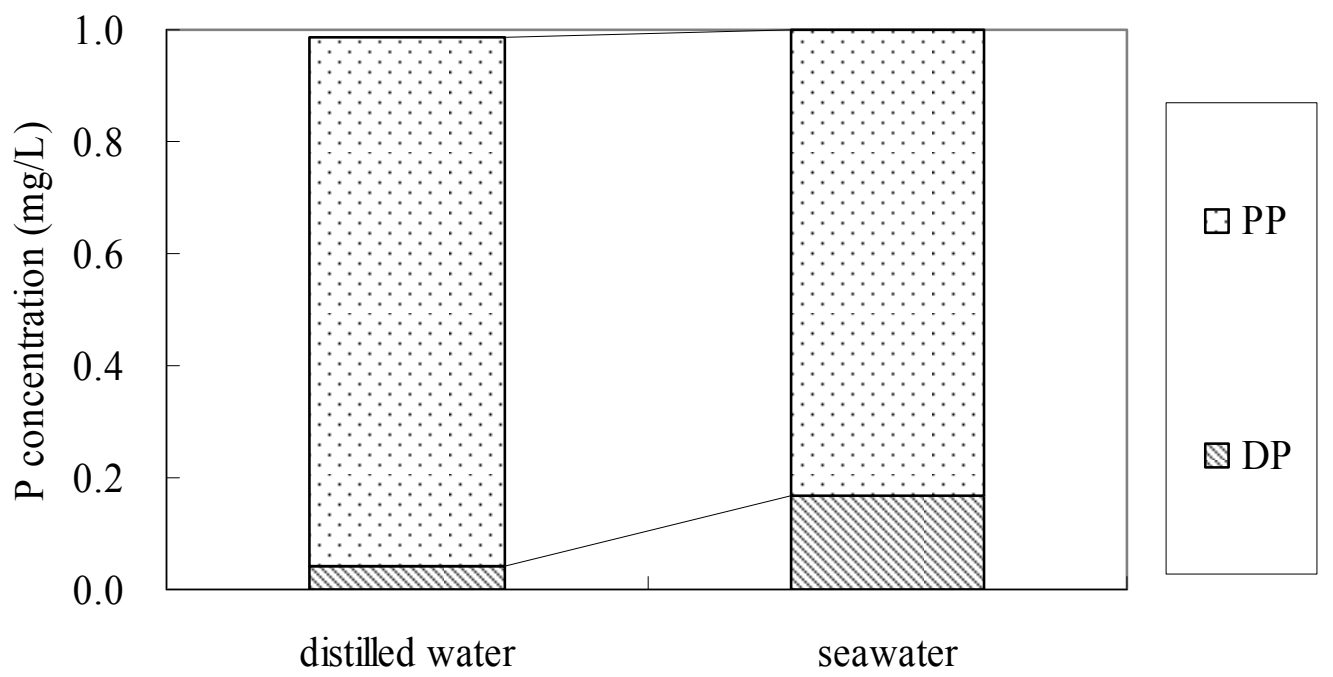

Figure 6 The concentrations of DP and PP after mixing $2 \mathrm{~g}$ of the soil of the agricultural area with $1 \mathrm{~L}$ of distilled water and artificial seawater. 


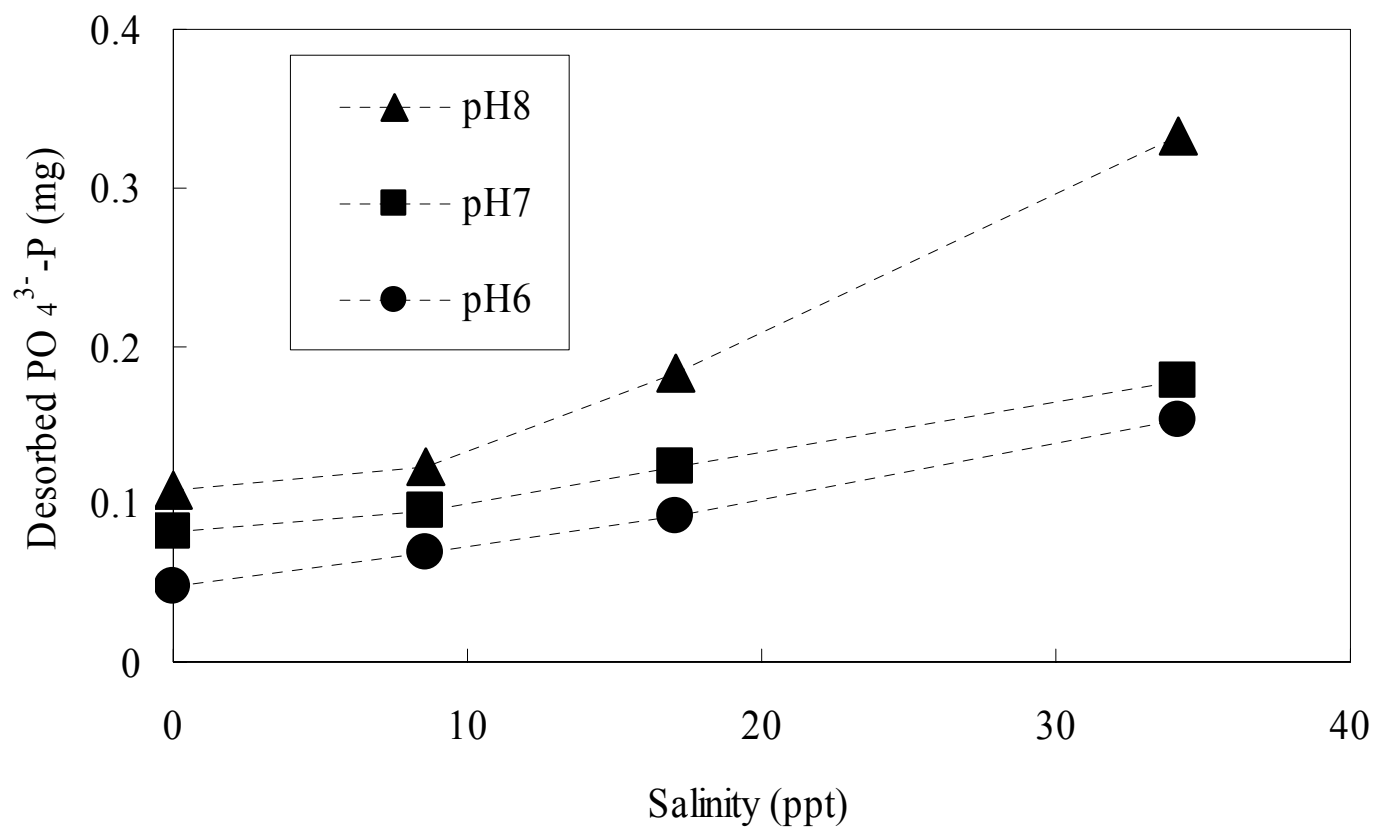

Figure 7. Relationships between the amounts of the desorption of $\mathrm{PO}_{4}{ }^{3-}$

-P from $2 \mathrm{~g}$ of soil of the agricultural area mixed with $1 \mathrm{~L}$ of artificial seawater and the salinity of the seawater at $\mathrm{pH} 6,7$ and 8 .

changed from the particulate form to the dissolved form in seawater. Figure 7 shows the relationships between the amounts of the desorption of $\mathrm{P}$ from SS and $\mathrm{pH}(6,7,8)$ and salinity $(34.2 \%, 17.1 \% 0,8.6 \%$, $0 \%$ ). At any $\mathrm{pH}$ the amount of desorption of DP increased with salinity. DP was desorbed more at $\mathrm{pH} 8$, and most of the desorbed DP in the tests was RP, suggesting that hydroxide ion can occupy sorption sites in the particulate matter which phosphate is adsorbed to (Nanzyo and Watanabe, 1981). Most TP discharged from agricultural areas in storm events was PP and some portion of the discharged PP could quickly convert to RP in the Mikawa coastal area, where the sea water was almost 8.

\section{CONCLUSION}

A survey of the three rivers running through dry fields in central Japan was carried out to clarify the characteristics of the runoff of phosphorus from agricultural areas and the impact of phosphorus discharge on the lake or bay downstream. The results of this study were the following:

1. The TP concentrations of the rivers greatly exceeded Japan's environmental quality standard for the closed bay the rivers flow into. Most of the TP discharged in storm events is in particulate form while the dissolved form is dominant in dry periods.

2. The concentrations and component ratio of phosphorus discharged from agricultural areas varied greatly varied during storm periods. PP was the dominant form of $\mathrm{P}$ in the rivers during storm periods, while most of phosphorus was dissolved in the dry periods.

3. The runoff characteristics of phosphorus were found to be the washout type, which means that the concentrations increase with the increase of discharge. There was a positive correlation between the runoff characteristics of PP and the proportion of agricultural land use, which means that the agricultural areas contributed a great deal to the PP discharge.

4. The result of an experimental desorption test indicated that about $10 \%$ of the PP loading from the lands can be dissolved in seawater, and that phosphate desorption depends on both $\mathrm{pH}$ and salinity. 


\section{ACKNOWLEDGEMENTS}

This work was supported in part by the River Environment Fund in charge of the Foundation of River and Watershed Environment, Japan, and The 21st Century COE Program "Ecological Engineering for Homeostatic Human Activities", from the ministry of Education, Culture, Sports, Science and Technology.

\section{REFERENCES}

Campbell, K. L. and Edwards, D. R. (2001). Phosphorus and water quality impacts, Agricultural nonpoint source pollution -Watershed management and hydrology, Lewis Publishers, pp.91-109

Inoue, T. and Ebise, S. (1991). Runoff characteristics of COD, BOD, C, N and P loadings from rivers to enclosed coastal seas, Marine Pollution Bulletin, 23, pp.11-14

Liss, P. S. (1976). Conservative and non-conservative behavior of dissolved constituents during estuarine mixing, Estuarine Chemistry, Academic Press, pp.93-130

Nanzyo, M. and Watanabe, Y. (1981). Material balance associated with phosphate sorption by amorphous clays, silica-alumina gel and synthetic goethite, Soil Science and Plant Nutrition, 27, pp.329-337

Tanaka, K. (1994). Effect of soil loading on the phosphorus cycle in estuarine and coastal marine environments, Bull. Nansei Natl. Fish. Res. Inst., 28, pp.73-119

Uusitalo, R., Yli-halla, M. and Turtola, E. (2000). Suspended soil as a source of potentially bioavailable phosphorus in surface runoff water from clay soil, Water Research, 34(9), pp.2477-2482

Yamada, T., Shimizu T. and Tachibana H. (2000). Runoff characteristics of nutrient loads from forest basins, Proc. of 4th International Conference on Diffuse Pollution, pp.255-262 